\title{
LOS CULTISMOS NO-GONGORINOS EN EL PRIMERO SUEÑO DE SOR JUANA INÉS DE LA CRUZ
}

Cuando en 1960 José Pascual Buxó estudia los cultismos en la poesía novohispana del siglo XVII, lo hace a base de dos obras que juzga representativas: el Triunfo Parténico, colección de composiciones a cargo de Sigüenza y Góngora, y el Primero sueño de Sor Juana Inés de la Cruz $^{1}$. En vez de elaborar un catálogo completo, Buxó apunta únicamente "algunos casos entresacados", explicando que una lista "habría resultado sustancialmente igual a las que figuran en el libro de Dámaso Alonso"2. Sin embargo, nuestro estudio de las voces cultas en el Primero sueño nos ha permitido confirmar que tal lista habría mostrado mayor diversidad de la sospechada por Buxós. En la silva sorjuanina solamente, hay más de 600 cultismos que no figuran en las listas de Alonso. De los aproximadamente 200 que sí están en ellas sólo poco más de la mitad proviene de la de "Vocablos cultos de la Soledad Primera" , aunque - a juzgar por lo que se ha dicho de la semejanza entre las silvas- se pensaría que el número sería más alto ${ }^{5}$. Aun cotejando el léxico culto del poema de Sor Juana con el vocabu-

1 Góngora en la poesía novohispánica, México, 1960. El capítulo sobre los cultismos ocupa las pp. 25-32.

${ }^{2} I$ lbid., p. 26. Buxó se refiere a La lengua poética de Góngora, que contiene varias listas de cultismos gongorinos, una selección de voces cultas de Mena, el Cartujano y Herrera, y un catálogo de vocablos que aparecen en censuras anticultistas del siglo xvn.

${ }^{3}$ Para un estudio y catálogo completo de los cultismos en el poema, véase el cap. 2 de mi tesis doctoral, "Dos recursos estilísticos en el Primero sueño de Sor Juana Inés de la Cruz: cultismo e hipérbaton", The Umiversity of Michigan, 1980, pp. 48-135. Por "cultismo" quiero decir las voces lingüisticamente cultas, o sea, aquellas palabras que no siguieron los cambios fonéticos experimentados por la masa de voces patrimoniales y originarias. Incluyo también en la enumeración los cultismos semánticos o de acepción (vocablos cuya forma puede ser culta o popular, que retienen el significado etimológico) así como voces de formación popular pero de determinado uso poético.

${ }^{4}$ De hecho el total habría sido mayor si Alonso hubiera incluido en su lista de toponímicos, nombres propios y todas las palabras cultas del poema. Peroél mismo explica, a modo de respuesta a una reseña de su libro, que no intentó ser exhaustivo: "Keniston $(H R, 5,1937, \mathrm{p}$. 353) ha notado que faltan en mi lista de cultismos palabras que lo son fonética y semánticamente, y tiene razón. Al llevar a realidad el propósito, resulta difícil mantenerlo de modo estricto... Estas líneas aspiran a tener un valor práctico más que rigurosamente científico" ( $\mathrm{La}$ lengua poética de Góngora, 3"i ed., Madrid, 1961, RFE, añejo 20, p. 77. nota 1).

${ }_{5}^{5}$ Valga como ejemplo la opinión de EI.JZABE.TH W WL.LACE quien en Sor Juana Inés de la Cruz: poetisa de corte y contento, México, 1944, dice que en su silva Sor Juana "imita abiertamente la Primera soledad de Góngora", p. 130. 
lario gongorino en su totalidad, observamos que la correspondencia no es tan estrecha como se ha supuesto: alrededor de un treinta por ciento de los cultismos empleados por Sor Juana en su poema más "exageradamente gongorino" nunca fueron utilizados por Góngora" .

Más de la tercera parte de estos cultismos no-gongorinos son epítetos. Los proverbiales esdrújulos, favoritos de Góngora, representan más del $10 \%$ de los epítetos cultos en el poema, pero la mitad no está en su vocabulario ${ }^{7}$. Nunca usó adjetivos como apolíneo, céntrico, científico, Elíseo, empírico, equívoco, evangélico, flemático, ínfimo, longísimo, mágico, ménfico, metafísico, mortífero, rápido, signífero, soporífero, súbito. En su mayoría son, como se podrá observar, vocabios derivados de las ciencias (céntrico, científico, empírico, equívoco, flemático, etc.), de la mitología (apolíneo, Elíseo, ménfico), así como compuestos típicos de Mena (mortífero, signífero, soporífero). Un buen número de los epítetos cultos (20) pertenece al grupo de palabras provenientes del latín con terminaciones -alis, -ales. De estas voces, que resultaban novedosas todavía en la época de Sor Juana, dos tercios no se encuentra en Góngora: arterial, artificial, corporal, general, inmaterial, intelectual, intencional, marcial, material, maternal, piramidal, racional, temporal, visual.

Asimismo, aproximadamente un tercio de los adjetivos con terminaciones -ans, -antis; -ens, -entis, del participio de presente (hay 31 en total) no figura en el léxico gongorino: aparente, confinante, incesante, independiente, indicante, inobediente, integrante, intercadente, perfeccionante, ventilante. A estos adjetivos deverbales ${ }^{8}$, se podrían añadir los participios pasivos empleados como adjetivos puros (suman 24), de los cuales los siguientes (más de la tercera parte) faltan en Góngora: entronizado, extenuado, fatigado, inadvertido, inanimado, inordinado, limitado, plumado, recuperado, segregado. La predilección de Sor Juana por los participios adjetivales (tanto los de presente como los pasivos) sugiere la filiación del epíteto culto en el Primero sueño con el "epíteto conceptista", así llamado para distinguirlo del que usa Góngora. Una de las notas más características de la epítesis conceptista es, precisamente, el empleo sistemático del partici-

"La cita viene de El.las Rivers, "El ambiguo Sueño de Sor Juana", CuH, 189 (1965), p. 276. De los 828 cultismos en el catálogo completo, 272 - que van enumerados más adelanteno están en Góngora. Para esta determinación me he servido del Vocabulario de las obras de don Luis de Góngora y Argote, Madrid, 1930, de Bernardo Alemany y Sel.fa aunque - según he comprobado- este estudio no es siempre de fiar. Palabras como "corpulento" $\mathrm{e}$ "inculcar", que se encuentran en la Soledad primera, no figuran. Como éstas puede haber más. Lo utilizo porque, por muchos que sean sus defectos (cf. la aguda reseña de Dámaso Alonso en $R F E, 18,1931,40-55$ ), es el único de esa magnitud que existe.

${ }^{7}$ Como señala Gonzalo Sobejano, los esdrújulos fueron los "epítetos formalmente preferidos por Góngora a causa de su acentuación particularmente eufónica" (El epiteto en la lírica española, Madrid, 1956, p. 319). De los poco más de 300 epítetos cultosen el Primero sueño,36 son esdrújulos.

${ }^{8}$ Adjetivos deverbales son aquéllos "de agente o participios de presente más o menos absueltos de su valor verbal", Sobejano, p. 327. 
pio adjetival, que como hemos visto da cuenta del veinte por ciento de los epítetos no-gongorinos en el poema ${ }^{9}$.

Como se percibirá en el catálogo de cultis mos no-gongorinos, los vocablos pertenecen a diversas esferas: hay términos de la escolástica (categoría, ente, estimativa, inmaterial, integrante, intelectivo, perfeccionante, etc.), cosmografía y geometría (céntrico, circular, circunscribir, confinante, conglobar, conticinio, cuantidad, dimensión, dimidiar, diurno, elevación, estatura, línea, recto, reducción, simetría, sublunar, superficie, universo, etc.); voces de la música (intercadente, longa, máxima, mensura, pautar); de la medicina (arterial, cerebro, científico, contagio, empírico, flemático, húmedo, membrana, musculoso, pulmón, quilo, respirante); y otros de uso general (ambiente, anhelo, aparente, apetecer, apreciar, exterior, mansión, susurro, etc.). La variada gama de palabras en este muestrario ya indica la divergencia entre el vocabulario de Sor Juana y el de Góngora. Si bien no podemos decir con Xirau - al menos desde el punto de vista del léxico culto- que el Primero sueño "acaba por no tener casi nada que ver con Góngora"10 (después de todo, más de 500 cultismos sí aparecen en sus obras), a través del estudio de los vocablos cultos hemos podido comprobar que el poema no es ni "imitación servil" ni "extensa imitación"" suya, y que la presencia de cultismos en sí no demuestra, como quiere Buxó, "la total dependencia de su modelo" ${ }^{\prime 2}$.

Junto a cada asiento del catálogo a continuación se encontrará la siguiente información: 1) la fecha de introducción del vocablo según el Breve diccionario etimológico (BDE) de Corominas o, si falta en éste, el Diccionario crítico etimológico ${ }^{13}$;2) si la palabra figura entre los cultismos literarios compilados por Colin Smith (C. Smith), que suplementa la información de Corominas ${ }^{14}$; 3 ) testimonio adicional del Diccionario de Autoridades (Aut.) u otras fuentes lexicográficas cuando lo creo oportuno; 4) si el cultismo fue empleado anterior-

${ }^{9}$ En "El epíteto conceptista" (RLit, 39, 1978, 7-25) José María Pozuelo Ivancos indica muchos autores, como Quevedo por ejemplo, que optaron por participios adjetivales antes que por epítetos a causa de su densidad expresiva, "puesto que un participio adjetival sostiene simultáneamente una función calificativa y la resultante del proceso o acción de un verbo", pp: $17-18$.

${ }^{10} \mathrm{R}_{\mathrm{Amon}} \mathrm{X}$ IRau, Genio y figura de Sor Juana Inés de la Cruz, Buenos Aires, 1967, p. 86.

${ }^{11}$ La primera cita de Francisco PiMEN TEL Historia crítica de la literatura y de las ciencias en México, $2^{\mathrm{a}}$ ed., México, Librería de la Enseñanza, 1890, p. 168. La segunda es de Josê María VIG,1L. "Sor Juana Inés de la Cruz", Revista Europea, $1^{0}$ de oct. de 1876, p. 433 (cit. en Sor Juana Inés de la Cruz, Poesías escogidas, ed. Antonio Elias de Molíns, Madrid, Lib. de Victoriano Suárez, 1901?, p. 12).

${ }^{12}$ Op. cit., p. 32.

${ }^{13}$ La información bibliográfica completa sobre éste y los demás trabajos citados a continuación se encontrará en la sección "Siglas y abreviaturas" que precede a la lista de cultismos.

${ }^{14}$ Apunto los casos en que un vocablo figura en la lista de Colin Smith porque, aunque BDE incorpora la gran mayoría de sus correcciones, Corominas no reproduce (por razones de espacio) la valiosa documentación que allí se encuentra. 
mente por Herrera y, en algunos casos, por otros autores como Manrique, Mena, el Cartujano, Garcilaso, fray Luis o Paravicino ${ }^{15}$; 5 ) si la palabra fue criticada por culta en el siglo XvII, según las censuras anticultistas (CA) recopiladas por Dámaso Alonso en La lengua poética de Góngora (LPG) ${ }^{16}$. Esta información permitirá observar al lector, en cada caso, el grado de difusión del vocablo, así como las coincidencias entre el léxico de Sor Juana y el de otros autores (como por ejemplo, Herrera) hasta ahora desatendidos en lo que atañe al Primero sueño.

Finalmente, antes de pasar a la lista, unas aclaraciones más: a) los números entre paréntesis que siguen a cada artículo indican el verso (o versos) del Primero sueño en que la palabra aparece; siempre que cito del poema lo hago por la edición de Méndez Plancarte $(O C, \mathrm{I}$, $335-59)$; b) si se trata de un cultismo semántico, el sentido etimológico va entre corchetes; c) los verbos figuran en infinitivo; sólo los participios pasivos usados como adjetivos puros van en un apartado diferente. Cuando en algunos casos (por ejemplo, en aquéllos en que no interviene explícitamente el agente) faltan criterios para decidir si se trata de un adjetivo verbal o de un genuino participio, lo introduzco como verbo.

\section{SigLAS Y ABREVIATURAS}

* = Según Corominas, la palabra no es fonéticamente culta.

$\mathrm{A}=$ Bernardo Alemany y Selfa, Vocabulario de las obras de don Luis de Góngora y Argote, Madrid, Tip. de RABM, 1930).

$\mathrm{AC}=$ Emilio Alarcos, listas de cultismos y palabras censuradas en el léxico de Paravicino. En "Los sermones de Paravicino", RFE, 24 (1937), 311-14.

Acad $_{2}=$ Real Academia Española, Diccionario de la lengua española, 19a ed., Espasa-Calpe, Madrid, 1970.

Aut. = Diccionario de Autoridades (1726-1739), ed. facsímil en 3 vols., Gredos, Madrid, 1976.

\footnotetext{
${ }^{15}$ Para Herrera me guío por el Vocabulario de Kossoff (Voc.), la lista de cultismos que lo precede (K), y también por las listas de Macrí (M). Nótese que Macrí, a diferencia de Kossoff, incluye en su estudio los cultismos de la edición de Pacheco y los de obras en prosa como las Anotaciones, y de ahí resultan algunas de las discrepancias entre las listas. Para Manrique, Mena y el Cartujano utilizo la selección de vocablos cultos (no son listas completas, sólo muestrarios) del libro de María Rosa Lida de Malkiel (MRL), Juan de Mena: poeta del prerrenacimiento español. Para los cultismos (especialmente los semánticos) en Garcilaso y fray Luis, empleo los trabajos de Rafael Lapesa (L) y, para los de Paravicino, las listas de Emilio Alarcos (AC).

${ }_{16}$ Cuando Dámaso Alonso introduce su "Lista de palabras afectadas según censuras y parodias literarias del siglo xvi", advierte que ha tenido que incluir ejemplos bastante separados temporalmente, y que "la censura, en algunas ocasiones, no tendría validez más que con relación a un breve período de años dentro del siglo" (LPG, p. 91). El caveat de Alonso es aún más necesario aquí, pues se trata de un texio alejado del poema gongorino - y de la mayor parte de las censuras - por varias décadas. El cotejo de su lista con la de vocablos cultos en el Primero sueño es útil, creemos, siempre y cuando se recuerde que para entonces algunas de esas palabras bien podrian haber pasado al uso popular.
} 
$\mathrm{BDE}=$ Joan Corominas, Breve diccionario etimológico de la lengua castellana, 3a ed., Gredos, Madrid, 1973.

Boyd-Bowman $=$ Peter Boyd-Bowman, Léxico hispanoamericano del siglo $x v i$, Tamesis, London, 1971.

$\mathrm{CA}=$ Censuras anticultistas recogidas por Dámaso Alonso en su "Lista de palabras afectadas según censuras y parodias literarias del siglo XVII", en $L P G$, pp. 95-108.

C. Smith $=$ Colin C. Smith, "Los cultismos literarios del Renacimiento: Pequeña adición al Diccionario crítico etimológico de Corominas", $B H i, 61$ (1959), 236-72. Si no se indica "s.v.", la palabra se encontrará en la lista de Smith por orden alfabético.

Cuervo $=$ Rufino J. Cuervo, Diccionario de construcción y régimen de la lengua castellana, 2 ts: A-B y C-D, Instituto Caro y Cuervo, Bogotá, 1953.

DCI = Dámaso Alonso, "Vocablos cultos de la Soledad Primera", en LPG, pp. $48-66$.

DCII = Dámaso Alonso, "Algunos cultismos gongorinos anteriores a la Soledad Primera y no existentes en ésta”, en LPG, pp. 77-79.

DCIII = Dámaso Alonso, lista de cultismos en una composición gongorina de 1580 , en LPG, p. 80.

DCIV = Dámaso Alonso, selección de cultismos del Laberinto de Mena (LPG, pp. 82-83) y de Herrera (LPG, p. 84).

DCE = Joan Corominas, Diccionario crítico etimológico de la lengua castellana, ed. 1954-1957.

Fontecha $=$ Carmen Fontecha, Glosario de voces comentadas en ediciones de textos clásicos, C.S.I.C., Madrid, 1941.

G. de Diego = Vicente García de Diego, Diccionario etimológico español e hispánico, S.A.E.T.A., Madrid, 1954.

$\mathrm{K}=$ David A. Kossoff, recopilación de cultismos en la obra poética de Herrera (exceptuando los que se encuentran en la edición de Pacheco), en Voc., pp. ix-xii.

$\mathrm{L}=$ Rafael Lapesa, "El cultísmo semántico en la poesía de Garcilaso" y "El cultismo en la poesía de fray Luis de León", recogidos en Poetas y prosistas de ayer $y$ de hoy: Veinte estudios de historia y crítica literarias, Gredos, Madrid, 1977, pp. 92-109 y 110-45, respectivamente.

LPG = Dámaso Alonso, La lengua poética de Góngora, 3a ed., RFE, Añejo $20,1961$.

$\mathrm{M}=$ Oreste Macrí, "Vocablos ideológicos y clentíficos" y "Vocablos de uso poético", en Fernando de Herrera, 2a ed., Gredos, Madrid, 1972, pp. 391-403 y 403-31, respectivamente.

Macrí, BBMP = Oreste Macrí, "Nuevas adiciones al Diccionario de J. Corominas con apéndice sobre neologismos en Juan Ramón", $B B M P$, 38 (1962), 231-384.

Malkiel, "Préstamos y cultismos" = Yakov Malkiel, "Préstamos y cultismos", RLiR, 21 (1957), 1-61.

Martín Alonso = Martín Alonso Pedraz, Enciclopedia del idioma, diccionario histórico y moderno de la lengua española (siglos xii al $x x$ ), etimológico, tecnológico, regional e hispanoamericano, 3 ts., Aguilar, Madrid, 1958.

Méndez Plancarte $=$ Sor Juana Inés de la Cruz, Obras Completas $(O C), \mathrm{t} .1$, ed., introd. y notas de A. Méndez Plancarte, F.C.E., México, 1951.

Menéndez Pidal, Manual = Ramón Menéndez Pidal, Manual de gramática histórica española, 5a ed., Lib. de Victoriano Suárez, Madrid, 1925. 
MRL = María Rosa Lida de Malkiel, Juan de Mena: poeta del prerrenacimiento español, El Colegio de México, México, 1951.

PS = Primero sueño.

R. de Gorog = Ralph de Gorog, "Pre-datings for the Breve diccionario etimológico de la lengua castellana”, RNo, 18 (1977), 230-36.

R. Marín = Francisco Rodríguez Marín, Dos mil quinientas voces castizas $y$ bien autorizadas, Tip. de $R A B M$, Madrid, 1922.(Archivos, Bibliotecas y Museos, 1922 ).

s.f. $=\operatorname{Sin}$ fecha.

Terlingen $=$ Juan $\mathrm{H}$. Terlingen, Los italianismos en español: desde la formación del idioma hasta principios del siglo xui, N.V. Noord-Hollandsche Uitgevers Maatschappij, Amsterdam, 1943.

Tesoro $=$ Samuel Gili Gaya, Tesoro Lexicográfico (1492-1726), t. 1 A-E, C.S.I.C., Madrid, 1960.

$\mathrm{V}=$ Antonio Vilanova, "Índice comentado de cultismos", en Las fuentes y los temas del "Polifemo" de Góngora, RFE, Anejo 66, t.2, 1957, pp. 807-872. El "Índice" está en orden alfabético, de modo que sólo indico las páginas si la cita proviene de otra sección del texto.

Voc. = David E. Kossoff, Vocabulario de la obra poética de Herrera, Real Academia Española, Madrid, 1966.

\section{VOCABLOS CULTOS NO-GONGORINOS EN EL "PRIMERO SUEÑO"}

abstraer (abstraído, 587): h. 1500 (BDE). CA.

agregado [sust.] (446): s.f. (BDE, DCE). Aut. trae documentación de la primera mitad del s. XVII.

Alcione (94): Las ediciones clásicas de PS traen "Almone". Vossler en su edición sugiere la variante "Alcione", aceptada por Méndez Planearte como "la lección indudable", $(O C, \mathrm{I}, 578)$, y recogida así en las sucesivas ediciones del poema. Sin embargo, en los últimos años han aparecido trabajos que abogan por la restauración de la lección original. Ver Manuel Corripio Rivero, "Una minucia en 'El Sueño de Sor Juana: ¿ Almone o Alcione?", $A b s, 29$ (1965), 472-81; y Audrey Lumsden-Kouvel y Alexander P. MacGregor, "The enchantress Almone revealed: A note on Sor Juana Inés de la Cruz' use of a classical source in the Primero Sueño"', RCEH, 2 (1977), nûm. 1, 65-71.

ambiente $(117,218): 1588$ (BDE).

ampo (748): princ. s. XVII (BDE). Corominas anota "de el lampo se pasó a el ampo. . . , aplicado especialmente a la blancura de la nieve". Con esta acepción, que es la empleada en PS, aparece en Fontecha, quien apunta que la voz fue comentada por Clemencín en su edición del Quijote. Sobre lampo, ya empleado por Herrera y Góngora (ver M, 417), dice Kossoff en su Vocabulario que "Herrera pos. tenía esta palabra por ital., como lo sentía las Casas". Corominas, no obstante, se inclina por su filiación con el catalán llamp. 
anhelo (429): princ. s. XVII (BDE).

antipatía $(-\mathrm{s}, 528): 1611$ (BDE). CA.

aparatoso $(-\mathrm{a}, 165)$ : s.f. (BDE, DCE). S. XVII $(A u t$.), dice que "viene del nombre aparatoso; pero no es muy usado".

aparente (755): princ. s. XV (BDE).

apetecer (857): h. 1580 (BDE).

apolíneo (-a, 537): h. 1400 (L). Para la cronología de este cultismo, Lapesa utilizó los datos de los ficheros de la Real Academia, donde encontró el vocablo registrado por primera vez en La vida $y$ las costumbres de los viejos filósofos. Fray Luis de León (L, 113). Acad.

apreciar (apreciada, 702): h. 1140 (BDE). Malkiel, en "Préstamos y cultismos", dice que Corominas (en DCE, donde da la misma fecha que en BDE) ni fecha ni define este vocablo rigurosamente (p. 32) y luego añade que 'aunque, juzgando por la norma fonológica, apreciar es cultismo, no deja de formar parte integrante del léxico español más castizo y arcaico" (p. 35). Es interesante notar que no se encuentra en Garcilaso (según Eduardo Sarmiento, Concordancias de las obras poeticas en castellano de Garcilaso de la Vega, Columbus, Ohio, 1970), Herrera ni Góngora.

aprehensivo (-a, 642) : 1515: "aprensivo" (BDE). En DCE Corominas da como fecha de entrada de "aprehensivo", "fin s. Xvi". C. Smith (s.v. prender) adelanta esta fecha a 1515.

aquileyo (-as, 385): Góngora emplea este vocablo como toponímico, o sea para referirse a la ciudad de Italia antigua (A). En PS se usa con el significado de "perteneciente a Aquiles", y falta en todas las fuentes consultadas. La etimología es sin duda muy semejante a la que trae Corominas de la voz aquilea: "Tom. del lat. achillea y éste del gr. akhilleios id., deriv. de Akhilleus 'Aquiles'"' (BDE).

arbitrio (862): princ. s. XIV (BDE). Fray Luis de León (L, 113). arduo (607): $2^{\circ}$ cuarto s. XV (BDE). Herrera (K).

arterial (207): $1636(\mathrm{BDE})$.

artificial (-es, 412): h. 1250 (BDE).

asaltar (asaltada, 940): 1605 (BDE: “asalto” = del italiano assalto). La fecha de Corominas se puede adelantar unos años, pues ya se encuentra en Herrera; véase la lista de italianismos en Voc., p. xiii, y también entre los cultismos (K).

asilo (268): h. 1560 (BDE).

asociar (asociado, 212): 1726 (BDE; también trae "asociado", pero s.f.). En DCE se explica que ambas formas (aunque no pudimos encontrar la segunda) están documentadas por primera vez en Aut., y que la etimología de "asociar" es "de associare, quiza por conducto del fr."' La presencia del vocablo en PS nos permite adelantar la fecha unos años. 
atemperar (atemperados, 256): princ. s. XVIII (BDE). Corominas (DCE) remite al Diccionario de Cuervo (I, 736), donde se aducen ejemplos de Jovellanos y otros autores del s. XVIII, y se señala que "el vocablo castellano parece introducción moderna, sin verdadera conexión histórica con el antiguo atemprar”. La acepción antigua, que por las citas que trae Cuervo se entiende que vale "refrenar, moderar", no es tampoco la usada en PS. Aqui' la "templada hoguera del calor humano" (v. 253) [= el es. tómago] envía al cerebro los vapores de "los atemperados [= templados] cuatro humores", uso que se ajusta a las acepciones modernas apuntadas por Cuervo: "Reducir alguna cosa a su temperamento"; "moderar, templar". La palabra falta en el $T e$ soro ("atemprar" no esta registrada tampoco) y en $A$ ut. Acad.

atraer (atrae, 635): med. s. XV (BDE). R. de Gorog (p. 231) adelanta la fecha a 1438 . Herrera (Voc.).

atropar (atropadas, 951): s.f. (DCE; "tropa" = tomado del francés troupe, 1605). Allí se agrega que es vocablo raro en castellano, salvo en Asturias, donde se usa con la acepción juntar, amontonar'. En Aut. sí aparece con el sentido militar que trae en PS (s.v. atropado, -a): "Lo que va en tropa, o en compañía de mucha gente sin orden" y da documentación de la primera mitad del s. XVI (Oviedo). Martín Alonso, también bajo el artículo "atropado", señala que la palabra ya está registrada en varios diccionarios de los siglos XVII y XVIII con el significado que nos interesa, y desde el siglo XVI para designar a plantas de ramas recogidas. En vista de todo esto parece extraño que la forma participial falte en Corominas y que del infinitivo diga que es "raro" en castellano.

aumentar (aumente, 390): $2^{0}$ cuarto s. XV (BDE). Herrera (K).

brecha (31): 1643; del francès breche (BDE).

bullicioso (840): s.f. (BDE, DCE; "bullicio" = 1220-50). Aparece en Aut., donde se da documentación del s. XVII.

cálculo (135): 2a mitad s. XVI; 'piedrecilla' (BDE).

cantidad (-es, 522): h. 1250 (BDE).

caos (550): princ. s. XV (BDE). CA.

carena (572): $1435-39 *$ (BDE). Si bien Corominas señala aquí que el vocablo viene del latín carina, Terlingen (pp. 266-67) lo da como italianismo (del it. carena).

catálogo (389) : 1533 (BDE).

categoría (-as, 582): 1611 (BDE). Aut. lo define como "término de la Lógica" y trae 1709 como fecha de primera documentación. causa $(143,531,623$; -as, 529): 1251 (BDE). Cartujano (MRL, 450: "causa primera"). En Góngora sólo aparece con la acepción de 'razón', como en el v. 143 dc PS (A).

céntrico (409) : 1633 (BDE).

cerebro $(254,868) ; 1251$ (BDE). 
certamen (766): 1560 (BDE).

científico (-a, 235): s. XIV (BDE).

cíngulo (324): 1490 (BDE).

circular [adj.] (144): 1433 (BDE).

circunferencia $(410,948):$ h. 1440 (BDE). C. Smith (s.v. preferir).

Cartujano (MRL, 450). Herrera (M, 393).

circunscribir (circunscribe, 218, 732): 1432-50 (BDE).

circunspecto (815): 1592 (BDE).

colocar (333; colocada, 425): s. XIV (BDE). Herrera (Voc.).

combinar (combinadas, 554): 1599 (BDE).

compendio $(658,692)$ : 1438 (BDE). Mena (MRL, 256).

comprehender (-lo, 769): falta en BDE, DCE; "comprender" $=$ h. $1200^{*}$. En PS, la grafía y el significado ('abarcar', con la vista y el entendimiento) lo acercan al latín comprehendere, propiamente 'abarcar', 'coger', según la definición en BDE, Aut. lo tiene con este sentido (s.v. comprehender): "Vale también entender, alcanzar, conocer, percebir y hacerse capaz de alguna cosa", y da documentación del s. XVI. Garcilaso (L, 94: con el sentido de 'percibir, ver').

comprehensión (450): falta en BDE, DCE; "comprensión" = s.f. Segưn el Tesoro, aparece en los diccionarios a partir de 1604. Aut. trae documentación del s. XVII. Con relación a este vocablo dice Méndez Plancarte: "Aquí, y en casos análogos, conservamos la grafía comprehender, no por la métrica (que mejor pediría comprender), sino por su sentido más latino de 'abarcar'..." $(O C, \mathrm{I}, 579)$.

comprimir (comprimiendo, 215): h. 1440 (BDE). C. Smith (s.v. exprimir).

confección (536): s. XVI (BDE).

confederar(confederados, 371): h. 1460 (BDE).

confinante (-s, 372): fin s. XVI (DCE).

conglobar (conglobado, 472): s.f. (BDE, DCE). s.f. (BDE, DCE). Aut. lo trae bajo el participio pasivo: "Lo assi unido y mezclado (tomando la figúra orbiculár ủ de globo)", y da documentación de mediados de s. XVII.

contagio (823): 1626 (BDE).

conticinio (151): s.f.; "raro, del lat. conticinium" (DCE). Falta en el Tesoro y en Aut., así como en todos los vocabularios poéticos consultados. Robert Ricard se ocupa del significado de esta palabra en 'A propos de 'conticinio' dans le Sueño de Sor Juana Inés de la Cruz", Les Lettres Romanes, 26 (1972), 249-54.

convertir ['volver, dirigir'] (convertida, 292): 1220-50 (BDE). Además del sentido corriente de 'transformar' (v. 871), Sor Juana emplea este verbo en su acepción latina: “[el alma] toda convertida / a su inmaterial ser y esencia bella, / aquella contemplaba, / participada de alto Ser, centella / que con similitud en sí goza- 
ba" (vs. 292-296); o sea, el alma, vuelta o dirigida a su inmaterial ser y esencia bella, contemplaba aquella esencia divina ("centella participada de alto Ser") que gozaba en sí. Fray Luis de León (L, 123). Garcilaso también emplea "convertir" como cultismo semántico, pero con otra acepción. Lapesa señala que lo usa como equivalente de 'mover el ánimo hacia un determinado fin' y de 'aplicarse, dedicarse' (L, pp. 95-96). Herrera (Voc.). corporal $(156,299,652)$ : 1220-50 (BDE). Manrique (MRL, 251), Herrera $(\mathrm{K})$.

craso[adj.] $(-\mathrm{a}, 35): 1550$ (BDE). Corominas señala en DCE, con relación a graso, que su "duplicado culto es craso. . . casi sólo empleado figuradamente". En PS el uso es literal, no figurado: "la materia crasa" vale por el aceite de las lamparillas del templo. El Tesoro registra el vocablo en diccionarios a partir de 1601. La primera documentación en Aut. es de 1632 (Lope, La Dorotea). cualidad (-es, 474, 524): 1490 (BDE).

cuantidad (302; -es, 241): h. 1250: "quantidad" (DCE). débil (933; -es, 508, 600): 1433 (BDE). C. Smith. Herrera (K). En Góngora sólo aparece "debilidad".

deleite (157): h. 1140; por vía semiculta (BDE). Herrera (Voc.).

denotar (denotando, 144): h. 1440 (BDE). C. Smith (s.v. nota).

desatento (563): falta en BDE, DCE. Figura en Aut., donde se da 1636 (Paravicino, "Adviento y Quaresma") como fecha de primera documentación.

desocupar (desocupado, 868): s.f. (BDE, DCE), Herrera (K).

desunir (desunidas, 555): s.f. (BDE, DCE). El Tesoro da 1604 como fecha de primera documentación.

desvalido (622): s.f. (BDE, DCE). El Tesoro lo encuentra registrado por primera vez en 1599. Herrera (Voc.). CA.

dimensión (-es, 402, 885): h. 1570 (BDE). C. Smith (s.v. medir).

dimidiar (dimidiaba, 152): s. XVIII. DCE, "Introducido en Aut. por el académico italiano Marqués de San Felipe, no es palabra castellana". Corominas llega a esta determinación basándose en el apartado "Demediar y dimidiar" del artículo de Emilio Cotarelo, "Semántica española" (BRAE, 7, 1920, 652-62). Pero no es ésta exactamente la tesis de Cotarelo, quien tampoco ofrece su parecer con tanta seguridad como para ser acogido sin más por Corominas. En su trabajo Cotarelo señala que después de buscar, sin éxito, en diccionarios y textos de los siglos XVI y XVII la voz dimidiar (aunque sí encuentra demediar), por fin "adivina" (ésta es la palabra que usa) que si fue recogida en $A u t$. se debe a que los compiladores vieron la palabra "en una obra de su compañero el italiano Marqués de San Felipe (murió en 1726)" (p. 662). Seguidamente advierte que es voz que "podemos calificar de extravagancia o desconocimiento de nuestro idioma". En vista de la presencia del vocablo en PS podemos descartar $-\mathrm{o}$ al 
menos cuestionar seriamente- la hipótesis de Cotarelo. La forma dimidiar se debe, con toda probabilidad, no al influjo del italiano, sino del latín dimidiäre. Como era de esperar (en vista de lo dicho por Cotarelo), el vocablo falta en todas las fuentes lexicográficas y poéticas consultadas. "Demediar" está documentado en el Tesoro a partir de 1492.

diminución (356): 1570: “disminución” (BDE). El Tesoro registra el vocablo a partir de 1570 . R. de Gorog adelanta la fecha a 1438. Góngora sólo emplea "diminuir” (A).

discernir (481; discierna, 179): $2^{\circ}$ cuarto s. XV (BDE). Herrera (K). disentir (disentía, 705): 1600 (BDE).

distintivo [sust.] (178): s.f. (DCE). Falta en el Tesoro. Aut. trae el significado que vemos en PS: "Usado como sustantivo, es la señal o insignia especial, que diferencia a alguno entre los demás. . . Lat. insignia", pero no lo documenta. En otro apartado ofrece una definición semejante, que también se aviene al uso en PS: "En la Escuéla es aquel predicado constitutivo del ser de alguna cosa en virtud del qual se distingue u diferencia realmente de otra. Lat. Distinctivum", y trae documentación del s. XVII.

distribuir (distribuyendo, 162): 1423 (BDE).

distributivo (970): 1490 (BDE). Aut. trae documentación de la primera mitad del s. XVII (Cervantes, Saavedra Fajardo).

diurno (-as, 153): 1607 (BDE). Aut. trae documentación de princ. s. XVII.

diversidad (543, 556): 1220-50 (BDE).

ejemplar [sust.] $(785,804,820): 1495$ (BDE).

elación (-es, 380): 1636 (BDE). Aut., sin embargo, ya trae documentación de mediados del s. XVI (la Historia imperial de Pedro Mexía $[+1551])$.

elevación (435): 1438 (BDE).

elevarse (se eleva, 660): 1490: "elevar" (BDE). Herrera (Voc.). "Elevado" en Góngora (A).

Elíseo (-s, 720): Herrera (Voc.).

embestir (embiste, 175; embestían, 951): 1554; tomado prob. del italiano investire (BDE). Aut., por su parte, opina que "sale del Latino Impetere, mudando la $p$ en $b$ ", y trae documentación del s. XVII.

empírico (-a, 533): 1611 (BDE). Aut. sólo trae el sustantivo, y lo define en términos peyorativos: "El médico que cura por sola la experiencia, sin haver estudiado la facultad de la Medicina, no haciendo caso de saber las complexiones y naturalezas de los hombres, ni poniendo cuidado en investigar las causas de las enfermedádes". La autoridad que cita, sin embargo, no emplea el término negativamente. Dice Antonio de Solís y Rivadeneyra en su Historia de la Nueva España (1685): "Ríase de los Empi- 
ricos la Medicina racionál: que a los principios todo fue de la experiencia" (lib. 5, cap. I). Sor Juana emplea el adjetivo, no el sustantivo, pero tampoco lo hace en son de crítica. Por el contrario, en esta sección del poema (vs. 516-39) se señala el provecho del empirismo frente al método puramente teórico.

ente (-s, 584): h. 1630 (BDE).

entronizado (-a, 660): falta en BDE, DCE; "entronizar" = s.f. (BDE, DCE). El Tesoro da 1604 como fecha de primera documentación. Falta en $A u t$.

entumecer (entumecidos, 860): 1615 (BDE).

equívoco [adj.] (479): 1433 (BDE).

esmero (342): s.f. BDE, DCE. En este último se explica que "esmerado" y "esmerarse" son probablemente semicultismos. Aut. trae documentación del s. XVII.

especie $(484,761$; -s, 403, 472, 551): 1438 (BDE). C. Smith. Mena (MRL, 256: "espeçies e formas").

estatura (355): h. 1440 (BDE). C. Smith (s.v. estar).

estimativa [sust.] (258): 1438 (BDE). Aut. lo documenta con una cita de Boscán (El cortesano, 1534).

evangélico (-a, 681): 1515 (BDE). En Góngora sólo se da "Evangelio", "evangelista" (A).

excepción (227): 1348 (BDE). El Tesoro trae, bajo "exempción", documentado a partir de 1607. Aut. define el término en la acepción jurídica con que se emplea en PS (el corazón y los pulmones son testigos de mayor excepción porque, aun durante el sueño, siguen dando indicios de vida, mientras los sentidos y la lengua parecen contradecirlos con su silencio cf. vs. 226-234): "En lo legal es la razón o motivo que se alega en defensa del derecho que uno pretende tener, oponiendose a la pretension y alegacion contraria, para rebatirla, y para que no le comprehenda ni perjudique, assi en la substáncia como en el modo de proceder. Tiene diversos nombres y especies". Trae documentación del s. XVI.

excesivo (706): 1438 (BDE).

exento ['libre'] (-as, 6, 181): 1438 (BDE). El Tesoro registra el vocablo a partir de 1601, en la obra de Francisco del Rosal ("exempto, que en lat. es libre y eximido"). C. Smith (s.v. redimir). Herrera (Voc.). Méndez Plancarte apunta su presencia en Ercilla, Tirso y Cervantes $(O C, 1,581)$.

explicar ['desplegar'] (738): 1438; propiamente 'desplegar, desenredar' (BDE). C. Smith (s.v. plegar). Herrera (Voc., aunque sólo en el sentido habitual).

extenuado $(-\mathrm{s}, 854)$ : princ. s. XVII (BDE). Aut. trae documentación de 1614 (Bernardo Aldrete, Antigüedades de España).

exterior [adj.] (193; -es, 401, 973): 1438 (BDE).

fantasma (-s, 869): 1220-50 (BDE). A propósito de palabras como 
ésta, tomadas del griego, Menéndez Pidal explica que "sólo los eruditos, que sabían que en latín eran neutros, tendían a usar [estos vocablos] en masculino" (Manual, p. 180). Sor Juana se ciñe aquí al uso vulgar, pues lo usa como femenino.

Faro (267): "Se usó como toponímico desde la Edad Media" (DCE). En este verso Sor Juana se refiere a la isla ("que de Faro / cristalino portento. .."), y no al sustantivo que se derivó por antonomasia, a pesar de lo que se lee en varias de las prosificaciones del poema. En ellas se interpreta como una alusión al Faro de Alejandría (véase, por ejemplo, Antologia minima de Sor Juana Inés de la Cruz, México, 1962, donde el verso se convierte en "portento cristalino del Faro de Alejandría", p. 141). Herrera sólo emplea la forma adjetival "Fario" (Voc.). Góngora únicamente usa el vocablo en otras acepciones $(\mathrm{V}, \mathrm{A})$.

fidelidad (564): 1490 (BDE).

fijo (-s, 343): 1256 (BDE). Herrera y Góngora sólo emplean la forma verbal "fijar" (K y A, respectivamente).

flemático (62): 1438 (BDE). C. Smith (s.v. flema).

funesto (-a, 1, 928, 950; -as. 52): h. 1580 (BDE). Herrera (K; M, 414). CA.

general[adj.] (-es, 584): 1220-50 (BDE).

gravoso (-a, 141): 1607* (BDE). La definición que da Aut. se aviene al uso en PS: "Cargoso, molesto, pesado, y en cierta manera intolerable". Los ejemplos que cita son de finales del s. XVII.

Harpócrates (76).

hemistiquio (397): princ. s. XVII (BDE).

historiador (-es, 388): h. 1295 (BDE).

Homero (399): Herrera (Voc.: “Omero").

horroroso (-s, 716): 1702 (BDE). La fecha de Corominas se puede adelantar unos años, dada la presencia del vocablo en PS.

húmedo [sust.] $(245,841): 1288$ (BDE). Méndez Plancarte explica que Sor Juana emplea la palabra para referirse al "húmedo radical", y cita ejemplos del s. XVI $(O C, 1,589-90)$. Aut. (s.v. húmedo radical) trae documentación del s. XVII.

imaginativa [sust.] (259): 1438 (BDE). Aut. lo define como "La potencia, o facultád de imaginar: y algunas veces lo mismo que Imaginación", y trae a Mena como primera documentación.

imaginativo (-a, 643): 1569 (BDE). C. Smith (s.v. imagen). Herrera (M, 398).

impeler (impele, 219): h. 1440 (BDE). "Impelido" en Herrera (K).

inadvertido (-as, 561): s.f. (BDE, DCE); "inadvertencia" = h. 1440 (BDE). Aut. trae documentación del s. XVIr. Herrera (K).

inanimado (620; -a, 647): princ. s. XVII (BDE).

incesante (243): s.f. (BDE, DCE). Aut. trae ejemplos del s. XVII.

incomportable (772): 1605 (Quijote) (DCE). Macrí, BBMP adelanta la fecha a h. 1580 (fray Luis de León). Aut. cita ejemplos de la 
segunda mitad del s. Xvi (Hernando del Castillo, Historia de Santo Domingo). Herrera (K).

incurrir (133): 1438 (BDE). C. Smith (s.v. correr).

independiente (762): s.f. (BDE, DCE). Aut. trae documentación de la primera mitad del s. XVII.

indicante (75): s.f. (DCE). Allí se añade a propósito de "indicar" que la primera documentación es de 1693 y que es "frecuente desde princ. s. XVIII, mas parece ser ajeno a la lengua del Siglo de Oro (falta Oudin, Covarr. Quijote, Góngora, R. de Alarcón), hoy de uso general". El vocablo, sin embargo, aparece censurado en un soneto de Lope (véase CA), y Dámaso Alonso lo registra además en dos diccionarios de la época (1679 y 1705). Aut. sólo consigna "indicante" como sustantivo (es un término médico), y no como adjetivo.

infimo (619; -a, 328): h. 1440 (BDE). Herrera (Voc.).

inflamar(inflama, 835): 1438 (BDE). Herrera (K).

informe [adj.] (549): 1490 (BDE). Aut. trae, bajo la acepción que mejor se aviene a PS ("Significa también sin forma o figura"), documentación del s. XVII.

inmaterial (293): s.f. (BDE, DCE). En Aut. figura bajo "inmaterial" y trae como primera documentación la Escala espiritual de fray Luis de Granada (h. 1580).

inmunidad (339): s. XVI (BDE).

innato $(-\mathrm{a}, 516): 2^{0}$ cuarto s. XV (BDE). C. Smith (s.v. nacer).

inobediente (-s, 41): falta BDE, DCE. Aut. indica como fecha de primera documentación la segunda mitad del s. XVI. Parece ser voz bastante generalizada. Se encuentra, por ejemplo, en la Historia de las Indias (1527-66) de Bartolomé de las Casas, donde hablando de Adán y Eva se dice que "al precepto divino fueron inobedientes" (Lib. I, cap. I, p. 24, México, 1951). Este uso, aplicado a la rebelión contra una divinidad, recuerda el verso en PS (las hijas de Minias fueron transformadas en murciélagos por haber sido "a la deidad de Baco inobedientes"), y apunta a una posible influencia eclesiástica en la retención de este latinismo. La palabra también se usó en otros contextos, como en la silva "El sueño" de Quevedo: "Cuidados veladores / hacen inobedientes mis dos ojos / a la ley de las horas" (vs. 7-9).

inordinado (550): falta en BDE, DCE. Aut. registra "inordenado" y da como fecha de primera documentación $c a .1636$ (Calderón, El jardín de Falerina). El vocablo en PS es más fiel a la radical latina, pues retiene la $i$ etimológica.

insensiblemente (610): h. 1440: "insensible" (BDE). C. Smith trae "insensible" (s.v. sentir).

integrante (-s, 492): s.f. BDE, DCE; “íntegro" = 1640 (BDE). Aut. define el vocablo ("Lo mismo que integrál"), pero no trae documentación. 
intelectivo (-a, 482): h. 1440 (BDE). C. Smith (s.v. inteligente). Aut. aporta documentación del s. XVIII.

intelectual (301; -es, 287, 441): h. 1440 (BDE). C. Smith (s.v. inteligente). Mena emplea "ynteleto" (MRL, 256). También el Cartujano, quien usa la frase "intelecto agente" (MRL, 450). Herrera $(\mathrm{M}, 398)$.

intencional (-es, 403): 1923 (BDE). Esta fecha de entrada tan tardía es un tanto sorprendente. Puede que Corominas se refiera a una acepción especial del vocablo, pero a lo único que remite en DCE es a la ed. de 1936 de $A$ cad., que trae acepciones semejantes a las que da $A$ ut., y a un trabajo de Fernando Ortiz sobre cubanismos, publicado en 1922. Pero ninguna de estas dos fuentes justificaría esa fecha. Sea como fuere, el adjetivo, en la acepción empleada por Sor Juana, aparece consignado en $A u t$. y definido así: "Lo que pertenece a los actos interiores del entendimiento o tiene ser por ellos. Dicese freqüentemente de las especies de los objetos que concurren al conocimiento de ellos. Lat. intentionalis". Lo documenta con una cita de la Historia de la Nueva España (1685) de Antonio de Solís.

intercadente (65): s.f. (DCE). Aut. trae documentación de la primera mitad del s. XVII.

interior (-es, 402, 666): 1438 (BDE). Mena (MRL, 138: "interiores"). interrumpirse (se interrumpía, 24): 1515: “interrumpir" (BDE). "Interrumpir" en Góngora (DCI, V).

introducirse (se introduce, 251): h. 1440: "introducir" (BDE). "Introducir" en Góngora (DCI).

jactancioso (-a, 744): s.f. (BDE), (DCE): “jactar” $=2^{\circ}$ cuarto s. $\mathrm{xv}$. "Jactancia" en Herrera (K).

jeroglífico (-s, 381): 1611 (BDE).

lánguido (-s, 199): 1444 (BDE). Herrera (M, 417). CA.

línea $(410 ;-s, 459,656,947): 1490$ (BDE).

linterna (873): princ. s. XIV (BDE). Aut. lo define en el sentido en que se usa en PS ("linterna mágica"), pero no trae documentación. Góngora sólo lo emplea en el sentido corriente (A).

longa (-s, 58): s.f.; 'nota de la música antigua', latinismo (DCE).

longísimo (-a, 269): "longo en la biblia moderna judeoespañola de Constantinopla" (DCE). Aut. trae "longuíssimo, ma" y dice lo siguiente: "Lo mismo que Larguíssimo. Es voz de poco uso". Lo documenta con una cita del 1617 (Cervantes, Persiles).

mansión (101): h. 1440 (BDE).

maquinoso (-a, 471): neologismo que vale 'complejo' y que, al parecer; no tuvo arraigo, pues falta en todas las fuentes consultadas (BDE, DCE, Aut., Acad., Martín Alonso, G. de Diego, R. Marín, etc.).

maravilloso $(654,842)$ : h. 1140 (BDE). Herrera (Voc.). "Maravilla" en Góngora (A). 
marcial (-es, 386): h. 1570 (BDE). C. Smith (s.v. Marte). Herrera (Voc.).

material [adj.] (194, -es, 400): 1220-50 (BDE).

maternal (-es, 628): h. 1440 (BDE). C. Smith (s.v. madre). Herrera y Góngora emplean "materno" (Voc. y DCII, respectivamente).

máxima [sust.] (-s, 58): s.f. (DCE). Aut. trae la acepción con que se usa en PS ("La primera nota ò punto de Música") y cita por el Compendio Matemático de Vicente Tosca (1709).

medianero (244; -a, 510): 1220-50* (BDE). Aut. da ejemplos de la segunda mitad del s. XVI y principios del XVII.

medio $(64,844,935)$ : h. $1140 *$; "con influjo culto de la forma italiana sobre la castellana, aceptado quizá para evitar una semejanza malsonante con el verbo mear" (BDE). Aunque Corominas no lo considera vocablo estrictamente culto, Vilanova sí, y explica que "como latinismo evidente impuesto por el idioma literario al lenguaje refinado y selecto, puede ser considerado como cultismo de introducción muy temprana, incorporado ya al lenguaje popular castellano varios siglos antes de Góngora”. Herrera (K). Góngora emplea el vocablo en la acepción de v. 64 ("parte entre uno y otro extremo de una cosa'; A), pero no como en los demás versos, donde vale 'diligencia o acción conveniente para conseguir alguna cosa' (cito según la definición en $A u t$.). $\mathrm{V}$ sólo lo trae en sentido de 'semí'.

membrana (-s, 50): 1444 (BDE). C. Smith (s.v. miembro).

ménfico (-as, 352).

mensura $(60 ;-$ s, 880$)$ : s.f. (BDE, DCE). Macrí, $B B M P$ da como primera documentación a Santillana (h. 1440).

mente (406, 432): 1444 (BDE). Mena (MRL, 252). CA "Mental" en Góngora (A).

metafísico [adj.] (-a, 583): med. s. XVII. Aut. no cita ejs.

mortífero (521); h. 1440 (BDE). Cartujano(MRL, 449; aquí se identifica el vocablo "mortífera" como "suntuoso compuesto" latino). musculoso (216): h. 1580 (BDE). "Músculo" en Góngora (DCI).

nativo (221): h. 1580 (BDE). En DCE se añade que fue "criticado como neologismo en Lope, Dorotea III, esc. iii". C. Smith (s.v. nacer). Herrera (M, 419).

necesitar (necesitado, 596): s. XVII (BDE), "necesitado"s. f. "Necessidad" en Góngora (DCI).

Nictimene (27).

nocivo (820; -as, 524): h. 1140 (BDE). C. Smith (s. v. nucir).

notar (nota, 241): h. 1140 (BDE). Herrera (K).

noticia $(725,822):$ 1220-50 (BDE). Aut. trae documentación de fines de s. XVI.

nutrimento (631): "ya figura en autores de princ. s. XVII" (DCE). C. Smith (s. v. nutrir) adelanta la fecha a h. 1400, pues lo encuentra en la Visión deleitable de A. de la Torre. 
obstáculo (443): 1607 (BDE). Esta fecha se puede adelantar unos años, pues el vocablo ya está consignado en el Diccionario de Palet (1604), según señala Dámaso Alonso en CA. Aut. trae documentación de principios de s. XVII. CA.

obtuso (-a, 70): 1444, 'no agudo' (BDE). Mena (MRL, 262: 'obtusos'; DCIV). CA.

ocasionar (644, 651): 1220-50 (BDE). “Ocasión” en Herrera (K) y en Góngora (DCII: “ocassión”).

operación $(515,575,835,867,974$; -es, 633): 1433 (BDE). Mena (MRL, 260).

oponer (opuestos, 370; oponiendo, 927): 1251 (BDE). Herrera (K). "Oponerse" en Góngora (A).

ornato (491): med. s. XV (BDE). C. Smith (s. v. ornar). "Ornar" en Herrera $(\mathrm{K})$ y en Góngora $(\mathrm{A})$.

panteón (796): 1611 (BDE). Aut: da documentación anterior: P. Juan de Torres, Philosophia moral de Principes (s. XVI). Paravicino (AC, 313).

Patmos (682).

pautar (pautando, 946): 1611 (BDE). Aut. trae la acepción que se aviene al v. 949 de PS, donde se dice que los rayos del sol van "pautando al Cielo la cerúlea plana": "En la música significa poner en el papel las rayas que corresponden", pero no trae documentación.

pavoroso $(914 ;$-a, 9, 57, 717): h. 950* (BDE). Herrera (DCIV, 84; Voc.).

peligrar (peligra, 822): 1220-50; semicultismo (BDE). Herrera (Voc.). perceptible (118): s. f. (BDE, DCE); "percepción"= princ. s. XVII (BDE). Aut. trae documentación de finales de s. XVII y principios del XVIII. Ya en Cartujano (MRL, 450: "perceptibles").

perenne (33): s. XVII (BDE). "Perennal" en Santillana (Macrí, BBMP). perfección (673): I ${ }^{\mathrm{a}}$ mitad s. XIII (BDE). Herrera (K).

perfeccionante $(-s, 490)$ : falta BDE, DCE; "perfeccionar" = s. f. (BDE). Falta en Aut. también. A propósito de "perficionar" dice allí: "Algunos dicen Perfeccionar, formando este verbo de la voz Perfección, pero más natural es Perficionar del Latino Perficere, que significa lo mismo". No trae ejemplos de "perfeccionar". Méndez Planearte señala que es término común en la filosofía escolástica $(O C, \mathrm{I}, 594)$. Acad.

pernicioso (904): 1611 (BDE). Aut trae documentación anterior, pues lo encuentra en la Historia natural y moral de las Indias del P. Acosta (1590).

perspectiva (879): 1438 (BDE). Herrera (M, 400-01). Paravicino (AC, 314).

perspicaz (440): 1737 (BDE). Corominas aparentemente da la fecha de $A$ ut. porque éste no trae el vocablo documentado. Su presencia en PS nos permite adelantar la fecha unos 50 años. 
piramidal (1, 404): 1438 (BDE). Mena (MRL, 268: “pyramidales”). "Pirámide" en Herrera (M, 422) y Góngora (DCII, V).

plana (949): 1611, 'cara del papel' (BDE). Aut. trae documentación del s. XVII. Góngora emplea otra acepción de la palabra (A, 'corregirle planas a uno', o sea, advertirle sus defectos).

plenitud (940): s. f. (BDE, DCE); "pleno" = princ. s. XVII, por vía culta (BDE). Aut. trae documentación de 1599 (Pedro de Ribadeneyra, Flos sanctorum).

plumado (-as, 336): s. f. BDE, DCE; "pluma" = 1195* (BDE). "Pluma" en Herrera y Góngora (Voc. y DCI, V, respectivamente).

Plutón $(54,717)$ : Herrera (Voc.).

portento $(268,690): 1584$ (BDE). Aut. trae documentación de fines del s. XVII.

potestad (109): I ${ }^{\text {a }}$ mitad s. XIV (BDE).

preceptor (751): s. f. (BDE, DCE). Aut. trae documentación de la segunda mitad del s. XVI.

precursor (-a, 197): h. 1620 (BDE). Aut. cita ejemplos de la primera mitad del s. XVII.

preferir (prefiere, 238): 1490 (BDE). Herrera (K).

preludio (905): princ. s. XVII (BDE).

presupuesto [sust.] (454): 1543 (BDE).

pretexto (932): princ. s. XVII (BDE). Esta fecha se puede adelantar, pues ya se encuentra en Herrera (M, 423: "pretesto").

primogénito (626): 1438 (BDE).

productivo (-a, 623): h. 1570 (BDE). Aut. no trae documentación. Góngora emplea "productor" (DCI) y "producir" (V). Herrera usa "producir" (K) también, pero "productivo" falta en ambos vocabularios. Sor Juana emplea el vocabulario en un contexto marcadamente escolástico-la "segunda causa productiva" es la Naturaleza. Acad. Martín Alonso lo registra en los siglos XIX -XX. proponer ['poner delante'] (propusiera, 820): princ. s. XIV (BDE). "Propuesto" en Herrera (K). Góngora también emplea el verbo, pero ni $\mathrm{K}$ ni $\mathrm{A}$ indican que se use en su acepción etimológica.

proporción (61): 1444 (BDE). C. Smith (s. v. porción). Sor Juana emplea este vocablo en la acepción musical: "torpe mensura [ritmo] perezosa / de mayor proporción. .." Con este sentido aparece en $A u t$., según la definición del Compendio matemático (1709) de Tosca, bajo el artículo "Proporción mayor ó Ternario mayor": "Uno de los tiempos que se usan en la Música. .." fray Luis de León (L, 113).

pulmón (213): h. 1250 (BDE). Aut. cita ejemplos del s. XVI (Andrés de Laguna y fr. Luis de Granada).

quilo (243): s. f. (BDE, DCE). Aut. trae (s. v. chylo) ejemplos de fray Luis de Granada (h. 1580) y de fray Gerónymo Gracián de la Madre de Dios (s. XVII). Méndez Plancarte señala que también se encuentra en el romance del Conde de la Granja, dedicado a 
Sor Juana e incluido en sus $O C$ (\# 49 bis), donde dice que la poetisa apuró "a Ciencias y Artes la esencia / y a la Erudición el quilo" (OC, I, 589).

racional (847): 1438 (BDE). C. Smith (s. v. razón).

rápido (330): h. $1490(\mathrm{BDE})$.

reclutar (reclutando, 907): 1690; del francés recruter (BDE). Aut. registra el vocablo en una obra de fr. Damián Cornejo (h. 1690), y de aquí probablemente Corominas fijó la fecha de entrada. La presencia de la palabra en PS nos permite adelantar esta fecha unos años.

recto (-a, 409): 1444 (BDE).

rectriz (rectrices, 667); latinismo de poco arraigo que falta en la mayoría de las fuentes consultadas (BDE, DCE, Aut., Acad., R. Marín, Boyd-Bowman, etc.), y que parte del latín rectrix, -icem, 'directora' derivado de rêgěre > cast. regir. A propósito de "regir", BDE señala h. 1350 como fecha de introducción; "rector" no entra hasta 1444, y "directriz", que aparece s. f. en DCE, parece ser de introducción tardía, pues falta en $A u t$. "Rectriz" figura en Martín Alonso como tecnicismo zoológico ("Dic. de las plumas largas que forman la cola de las aves y que a manera de timón sirven para regularizar el vuelo") y también en el Diccionario de mejicanismos, 2a ed. México, 1974, de Francisco $\mathrm{H}$ Santamaría ("Remera, plumas grandes con que terminan las alas de las aves"), pero no traen fecha de introducción. Esta definición no se aviene mal al sentido en PS. En este pasaje se explica que las potencias interiores (el entendimiento, la voluntad y la memoria) son tres rectrices que ennoblecen al Hombre, "bisagra engazadora" que se eleva sobre todas las formas inferiores y que es señora de las demás criaturas (vs. 655-70). Las potencias interiores son como tres plumas remeras, pues facilitan el vuelo de esta criatura a un plano más elevado en la Cadena de Júpiter o Escala del Ser. Méndez Planearte no hace ningún comentario en especial con relación a esta palabra en sus "Notas textuales" $(O C, \mathrm{I}, 597)$, y en la "Prosificación" del poema sólo dice que son las potencias "rectrices o dirigentes de nuestra vida" $(O C, \mathrm{I}$, 613). Hay que recordar que ambas acepciones ('remera', 'dirigente') mantienen un parentesco etimológico con "regir". Las dos lecciones, en todo caso, se complementan.

recuperado (-s, 223): 1607; duplicado culto de "recobrar" (BDE). Aut. no trae documentación.

recurso (516): h. 1440 (BDE). Aut. cita ejemplos de fines del siglo XVI (P. Mariana, Historia de España, 1592-1605) y del s. XVII (Paravicino).

reducción (583): 1595 (BDE). CA.

reducirse (577): 1438: "reducir" (BDE). El vocablo en este verso se usa en sentido de limitarse' ("juzgo conveniente / a singular 
asunto reducirse"), y así lo define Aut.: "Moderarse, arreglarse o ceñirse en el modo de vida o porte" (no trae documentación). Usado reflexivamente y con esta acepción, no se encuentra en los vocabularios poéticos consultados.

refleja [sust.] (573): falta en BDE, DCE; "reflejo = princ. s. XVII (BDE). En $A u t$. aparece con la acepción que trae en Reflexión en el sentido metaphórico. Lat. Consideratio". No da ejemplos. regio (140): h. 1440 (BDE).

regular [adj.] (304): 1490 (BDE).

relativo (595): 1490 (BDE). Aut. trae documentación del s. XVII.

remoto (-a, 197, 239, 825): 1444 (BDE). C. Smith (s. v. mover). Herrera (Voc.).

reportar (reportado, 575): h. 1440 (BDE). C. Smith (s. v. portar). resolver (resolvieron, 872): h. 1440 (BDE). Herrera (Voc.). "Resolverse" en Góngora (A).

respirante (212): s. f. (DCE). "Respirar" $=1220-50 *$ (BDE). Falta en $A$ ut. "Respirar" en Herrera (K) y en Góngora (A).

retórico [sust.] (519): fin s. XII (BDE). En DCE se añade lo siguiente: "I ${ }^{\mathrm{a}}$ doc. fin s. XII, Auto de los Reyes Magos. Después de este ej. aislado, es palabra rara en la Edad Media. La emplea A. Pal. ... y la registra Nebr. ... Aut. trae ejs. clásicos. Ya en el s. $\mathrm{XVI}$ el vocablo había alcanzado un grado considerable de vulgarización, según muestra la existencia de formas vulgares, por lo menos en el abstracto femenino correspondiente". Macrí, BBMP. lo encuentra también en Santillana (h. 1440). Aunque Góngora sólo usa la forma adjetival en el Polifemo, $\mathrm{V}$ también trae ejemplos del uso del sustantivo en otros autores. "Retórica" (sust.) en DCII.

segregado $(-\mathrm{a}, 761)$ : falta en BDE, DCE: "segregar" = princ. s. XVII (BDE). Aut. trae documentación del s. XVII.

segregar (segrega, 635): princ. s. XVII (BDE). Paravicino (Aut.).

sensible (-s, 665): h. 1440 (BDE). C. Smith (s. v. sentir). Cartujano (MRL, 450).

separadamente (578): 1515: "separar" (DCE). Aut. trae documentación del s. XVII.

separar (separada, 197; separadas, 553): 1515 (BDE). R. de Gorog (p. 234) adelanta la fecha a 1438. Herrera (Voc.).

serie $(391,617)$ : 1499 (BDE).

signífero (-a, 918): s. f. (DCE). Aut. trae documentación del s. XVII. silencioso $(20,76)$ : s. XVII (BDE). Sin documentación en $A$ ut. "Silencio" en Herrera y Góngora (K; DCI, V, respectivamente).

simetría (354): med. s. XV (BDE).

similitud (296): h. 1440 (BDE).

simpatía (-s, 527): 1611 (BDE).

simulacro (-s, 258): h. 1580 (BDE). Herrera (K; M, 427). El vocablo 
figura en Paravicino, pero con la acepción de 'estatua de una divinidad', distinto al uso en PS (AC, 314).

simular (simulara, 816): s. $\mathrm{XV}$ (BDE).

singular $(577,824)$ : 1220-50 (BDE). Herrera (K). Góngora emplea el vocablo, pero sólo con sentido de 'extraordinario', y no 'individual', como en PS (A).

sociable (419): 1515 (BDE). C. Smith (s. v. socio).

soporífero [adj.] (-s, 846): s. f. (BDE, DCE); "sopor" = 1739 (BDE). Aut. recoge testimonio de 1629 (Villamediana, Fábula de Faetón).

súbito (-s, 498): 1403 (BDE). Herrera (K).

sublunar (439; -es, 286): falta en BDE, DCE. Figura en $A$ ut. con documentación de Gabriel Álvarez de Toledo (+ 1714). G. de Diego.

substancia $(246,638,839)$ : 1220-50: "sustancia" (BDE). En DCE se explica que "la Acad. escribe substancia, como ya A. Pal." (se refiere al Vocabulario de Alonso de Palencia, 1490). CA trae la palabra, pero con otra acepción: "[en] substancia".

sucesivo (598): s. f. (BDE, DCE); "sucesión" = 1433 (BDE). Aut. documenta el vocablo con una cita de la Historia de la Iglesia y del Mundo (1713) de Gabriel Álvarez de Toledo.

sumiso (-as, 21): s. f. (BDE, DCE). Aut. define el vocablo, pero no lo documenta. La palabra aparece en el Quijote, donde se usa-como en PS - hablando de la voz. Véase el comentario de Rodríguez Marín en su ed. de 1928, registrado en Fontecha ("En voz sumisa" = 'en voz baja').

superficie $(267,886)$ : h. 1440 (BDE). "Superficial" en Paravicino $(\mathrm{AC}, 314)$.

susurro (83): 1607 (BDE). "Susurrar" en Herrera (K).

sutileza (s, 386): 1220-50* (BDE). Herrera (K).

temporal [adj.] (198): 1220-50 (BDE). Aut. trae documentación de mediados del s. XVI.

tenaz (263): 1515 (BDE). C. Smith (s. v. tener).

terrestre (631): h. 1440 (BDE). C. Smith (s. v. tierra). Herrera (K).

tiara (184): h. 1250 (BDE). Mena (DCIV). Herrera (DCIV; Voc.).

tipo (803; -s, 401): 1615 (BDE). Aut. trae ejemplos del s. XVII (s. v. typo).

tornasol (749): 1438; “quizá tomado del it. tornasole" (BDE). Aut. trae documentación del s. XVI.

transformar (transformó, 95; transformada, 96; -adas, 43; -ado, 838): 1220-50 (BDE). Herrera (K).

transmontante (-s, 891): falta de BDE, DCE; "transmontar" = s. f. (DCE). Falta en $A$ ut., sin embargo, bajo "tramontar" trae la definición que se ajusta al uso en PS (donde se explica que el sol despide al antípoda opuesto "con transmontantes rayos"): “...Dícese particularmente del Sol, quando en su ocaso se oculta de nues- 
tro Horizonte detrás de los montes. Dícese también Trasmontar". Góngora sólo emplea el italianismo "tramontar" (DCII), derivado de tramontarse (véase también Terlingen, pp. 228-229, sobre "tramontana"). Tal y como aparece en PS el vocablo parece ser de origen latino, derivado de transmontanus, a, um.

trasuntar (trasunta, 407): 1739 (BDE). Corominas no lo encuentra antes de $A u t$. (donde aparece sin documentación), y esto explica la fecha de entrada tan tardía. La presencia del vocablo en PS permite adelantar esta fecha unos 50 años. "Trasunto" en fray Luis (L, 113), Herrera (Voc.) y Góngora (A).

triforme (721): s. f. (DCE). Aut. dice: "Es epithéto, que los Poetas dan à la fabulosa Deidad de Diana. Es del Latino Triformis"; da documentación del s. XVII. Dámaso Alonso registra la palabra en Mena y en el Vocabulario de Minshew de 1617 (CA).

unión $(387,699,840)$ : 1220-50 (BDE). Herrera (Voc.).

universal [sust.] (-es, 588): 1427 (BDE). C. Smith (s. v. verter). Ni Corominas ni Smith aclaran si se refieren (en sus fechas de primera documentación) al adjetivo o al sustantivo, pero $A$ ut., que trae ambos, registra el sustantivo (término de la lógica) por primera vez a principios del s. XVII (Quevedo, Obras Pósthumas).

universo (489): 1438 (BDE). C. Smith (s. v. verter).

usurpador (-a, 911): 1438 (BDE). C. Smith (s. v. uso). Herrera (K). "Usurpar" en Góngora (A).

vegetable (625): princ. s. XVII (DCE). C. Smith adelanta esta fecha a h. 1440 (s. v. vegetal).

vegetativo (200): $2^{\circ}$ cuarto s. XV (BDE). C. Smith (s. v. vegetal). ventilante (562): falta BDE, DCE; "ventilar" $=1490$ (BDE). Falta en Aut. también. "Ventilar" en Góngora (A).

veterano [adj.] (-as, 909): s. XVII (BDE).

vigilancia $(-\mathrm{s}, 111): 2^{\circ}$ cuarto s. XV (BDE). C. Smith (s. v. velar). Garcilaso (M, 431: "vigilança").

visible (-s, 497, 971): 1438 (BDE). Cartujano (MRL, 450). Aut. trae documentación de la segunda mitad del s. XVI y de principios del XVII.

visual (368; -es, 459): 1580 (BDE). Herrera (M, 403).

volante [sust.] (206): s. XIV (BDE). Corominas no define el vocablo en BDE, pero las acepciones que trae en DCE no se avienen al sentido en PS, donde -hablando del corazón- se le llama perifrásticamente "el del reloj humano / vital volante" (vs. 205-06). Con esta acepción figura en Aut. ("En el Relox es una pieza, que hiriendo en la rueda de Santa Catalina, le regula, introduciéndose en los dientes de ella"), pero no trae documentación. Góngora sólo emplea el adjetivo verbal (A).

Rosa Perelmuter Pérez 